\title{
Poor sleep quality in migraine and probable migraine: a population study
}

\author{
Tae-Jin Song ${ }^{1}$, Soo-Jin Cho ${ }^{2}$, Won-Joo Kim ${ }^{3}$, Kwang Ik Yang ${ }^{4}$, Chang-Ho Yun ${ }^{5}$ and Min Kyung Chu ${ }^{6 *}$ (D)
}

\begin{abstract}
Background: Probable migraine (PM) is a subtype of migraine that is prevalent in the general population. Previous studies have shown that poor sleep quality is common among migraineurs and is associated with an exacerbation of migraine symptoms. However, information on the prevalence and clinical implication of poor sleep quality among individuals with PM is scarce. Thus, the aim of this study was to assess the prevalence and clinical impact of poor sleep quality in individuals with PM in comparison with those with migraine.

Methods: Two-stage cluster random sampling was used to perform the survey for sleep and headache in Korean general population. Participants with Pittsburgh Sleep Quality Index $>5$ were considered as having poor sleep quality.
\end{abstract}

Results: Of 2695 participants, 379 (14.1\%) had PM and 715 (26.5\%) had poor sleep quality. Prevalence of poor sleep quality was $35.4 \%$ in the PM group, which was lower than that in the migraine group (47.6\%, $p=0.011$ ), but higher than that in the non-headache group $(21.4 \%, p<0.001)$. The PM participants with poor sleep quality showed increased headache frequency (median [interquartile range]: 2.0 [0.3-4.0] vs. 1.0 [0.2-2.0]; $p=0.001$ ) and headache intensity (visual analogue scale, 6.0 [4.0-7.0] vs. 5.0 [3.5-6.0]; $p=0.003$ ) compared to PM participants who had no poor sleep quality.

Conclusions: Poor sleep quality was prevalent among participants with PM. It was associated with an exacerbation of PM symptoms. Our findings suggest that proper evaluation and treatment for poor sleep quality are needed in the management of PM.

Keywords: Headache, Migraine, Pittsburgh sleep quality index, Sleep, Sleep quality

\section{Background}

Probable migraine (PM) is classified when one of diagnostic criteria of migraine in the third edition of the international classification of headache disorders (ICHD-3) is not applicable [1]. Probable migraine affects approximately $5-10 \%$ of the general population. It causes significant amount of disability owing to its symptoms such as migraine [2-4]. Although previous studies have demonstrated that patients with PM have relatively milder headache symptoms compared to individuals with migraine $[3,5]$, many patients with PM experience poor quality of life related to health with considerable disability [4].

\footnotetext{
* Correspondence: chumk@yonsei.ac.kr

${ }^{6}$ Department of Neurology, Yonsei University College of Medicine, 50-1

Yonsei-ro, Seodaemoon-gu, Seoul 03722, South Korea

Full list of author information is available at the end of the article
}

Previous researches have revealed that sleep disturbances are frequent among migraineurs. Accompanying insomnia is more frequently noted in migraineurs than that in non-migraineurs [6]. Additionally, excessive daytime sleepiness is more prevalent among migraineurs. It is associated with worsening migraine symptoms [7]. Habitual snoring and bruxism are known to be risk factors of chronic migraine, a chronic form of migraine showing more severe symptoms and more frequent comorbidities compared to episodic migraine [8,9]. Restless legs syndrome is also significantly associated with migraine [10].

Both sleep quantity and quality are important not only for health, but also for well-being [11]. Sleep studies have demonstrated that duration of sleep does not differ between non-migraineurs and migraineurs [12, 13]. Therefore, difference in sleep quality may explain the 
higher sleep disturbance in migraineurs. Several studies have shown that poor sleep quality in migraineurs is more frequently noted compared to that in non-migraine individuals with headache $[14,15]$. Moreover, migraineurs who had poor sleep quality showed more frequent headache as well as symptoms of depression and anxiety [16].

Although PM is a common headache disorder, information about prevalence and clinical impact of poor sleep quality in individuals with PM is limited. We hypothesized that poor sleep quality would be prevalent in participants with PM and that it would be associated with an aggravation of clinical presentation of PM, as in the case with migraine. The Korean Headache-Sleep Study (KHSS) is a nationwide, general population-based survey about headache and sleep. The KHSS may give us a chance to investigate the relationship of PM with poor sleep quality. Thus, the aim of this study was to evaluate the prevalence and impact of poor sleep quality among participants with PM and those with migraine using data of the KHSS. Factors associated with poor sleep quality in participants with PM were also assessed.

\section{Methods}

\section{Survey}

KHSS is a nation-wide and cross-sectional study regarding headache and sleep characteristics among adult (1969 years old) across Korean general population. Detailed protocol and methods of KHSS were described elsewhere [17]. Briefly, KHSS used two-stage random sampling methods. The study population of KHSS was based on the distribution of Korean population except Jeju-island [17]. To prevent interest bias, we informed all participants that our survey theme was a social health issue than neurological disorders such as headache and sleep problems. The survey was conducted by door-to-door visits and face-to-face interviews, using a structured questionnaire. The questionnaire covered information regarding characteristics of headache, sleep, anxiety, and depression. All interviewers were not medical related workers. They were members of Gallup Korea. The KHSS was approved by the Institutional Review Board of Hallym University Sacred Heart Hospital (approval No. 2011-I077). We received written consent from all participants before the survey interview. The survey was performed from November 2011 to January 2012.

\section{Diagnosis of migraine and PM}

Migraine and PM were diagnosed based on ICHD-2 diagnostic criteria which was valid at that time [18]. Migraine was defined based on code 1.1 migraine without aura of ICHD-2 [18]. If a participant satisfied A, B, C, and $\mathrm{D}$ criteria of 1.1 migraine without aura, she/he was classified as having migraine. If one of criteria for migraine was not satisfied, the participant was classified as having PM. It is difficult to define code 1.2.1 migraine with aura or code 1.6.2 PM with aura in epidemiological study using questionnaire survey methods [19]. Therefore, our study did not estimate the presence of aura. Our study's migraine included both code 1.1 migraine without aura and code 1.2 migraine with aura [18] while PM included both code 1.6.1 PM without aura and code 1.6.2 PM with aura [18]. Our study questionnaire exhibited a sensitivity of $75.0 \%$ and a specificity of $88.2 \%$ in migraine diagnosis compared to doctor's diagnosis via telephone interview and result in the survey [20]. Frequency of headache per month, visual analogue scale (VAS) for headache intensity, and Headache Impact Test-6 (HIT-6) for impact of headache was investigated. Non-headache participants were defined as those who reported no headache during the previous year.

\section{Poor sleep quality, anxiety, and depression}

Pittsburgh Sleep Quality Index (PSQI) was applied to assess sleep quality. Participants with total PSQI score $>5$ were defined as having poor sleep quality [21]. We also investigated each component score of PSQI such as subjective quality of sleep, latency of sleep, duration of sleep, habitual sleep insufficiency, disturbance of sleep, use of hypnotics, and dysfunction at daytime [21]. Goldberg Anxiety Scale was used for the diagnosis of anxiety. The Goldberg Anxiety Scale includes four screening items and five supplementary items [22, 23]. Participants who presented positive answers with more than two of screening items or with more than five of all scale items were classified as persons with anxiety. The Korean version of Goldberg Anxiety Scale was validated in previous studies, with a sensitivity of $82.0 \%$ and a specificity of 94.4\% [23, 24]. Patient Health Questionnaire-9 (PHQ-9) was applied to investigate the presence of depression [25]. In this scoring system, presence of depression was defined as 10 points or more. The Korean version of PHQ-9 was also validated with a sensitivity of $81.1 \%$ and a specificity of $89.9 \%$ [26].

\section{Statistical analyses}

All statistical analyses were performed using SPSS 22.0 (IBM, Armonk, NY, USA). Kolmogorov-Smirnov test was used to check normal distribution for continuous variables. If variables showed normal distribution, independent $\mathrm{t}$-test or one-way analysis of variance was used. If variables did not show normal distribution, Mann-Whitney U-test or Kruskal-Wallis test was performed. Categorical variables were analysed using Chi-square test or Fisher's exact test. We used Mann -Whitney $U$-test to compare headache frequency per month, VAS score for headache intensity, and HIT-6 
score between participants had PM with and without poor sleep quality.

For assessing factors contributing to poor sleep quality among participants with PM, we performed multivariable linear regression analyses after adjusting sociodemographic variables (age, sex, residential area size, and level of education), GAS score for anxiety, PHQ-9 score for depression, frequency of headache (per month), and intensity of headache (VAS score). Statistical significance was considered when $p$ value (two-tailed) was less than 0.05 .

\section{Results}

\section{Survey}

We interviewed 7430 people and 3114 people who agreed to participate in our study (58.1\% of rejection rate). Of these, 419 people withdraw participation during the interview. Finally, 2695 people completed our survey (36.3\% of cooperation rate, Fig. 1). Distribution of sex, age, residence size, or education level of our sample was not significantly different from that in the general population in Korea (Table 1).

\section{Prevalence of migraine and PM}

Of 2695 subjects included in our study, 1273 (47.2\%) had at least one headache over the past year, including 143 (5.3\%) migraineurs and 379 (14.1\%) who had PM. Seven hundred and fifteen (26.5\%) participants had poor sleep quality (Table 1). The prevalence of PM was the highest $(16.8 \%)$ in $30-39$ and $40-49$ age groups. Of 379 PM participants, 339 (89.5\%), 29 (7.7\%), and 11 (2.8\%) missed criterion B (typical duration of headache), criterion $\mathrm{C}$ (typical headache characteristics), and criterion D (typical accompanying symptoms) of code 1.1 migraine diagnostic criteria, respectively.

\section{Prevalence of poor sleep quality and comparison of PSQI score according to headache diagnosis}

The prevalence of poor sleep quality was significantly higher in participants with PM (35.4\%) than that in participants with non-headache $(21.0 \%, p<0.001)$, but lower than that in participants with migraine $(47.6 \%, p=$ 0.011). Regarding PSQI, component scores for latency of sleep (mean \pm standard deviation) $(1.1 \pm 1.0$ vs. $0.8 \pm 0.9$, $p=0.001)$, sleep duration ( $0.6 \pm 0.8$ vs. $0.4 \pm 0.8, p=$ $0.001)$, sleep disturbance $(0.9 \pm 0.6$ vs. $0.8 \pm 0.5, p=$ $0.001)$, use of sleeping medication $(0.1 \pm 0.4$ vs. $0.0 \pm 0.2$, $p=0.001)$, daytime dysfunction ( $0.8 \pm 0.7$ vs. $0.5 \pm 0.6, p$ $=0.001)$, and total score $(5.2 \pm 2.4$ vs. $4.2 \pm 1.9, p=0.001)$ were higher in PM participants than those in non-headache participants. However, PSQI component scores for subjective sleep quality $(1.7 \pm 0.7$ vs. $1.7 \pm 0.8$, $p=0.879)$ and habitual sleep efficacy $(0.0 \pm 0.3$ vs. $0.0 \pm$ $1.5, p=0.119)$ did not significantly differ between PM and non-headache participants. When comparing PM participants with migraineurs, PSQI component scores for sleep latency and sleep disturbance as well as total PSQI score were higher in participants with migraine than those in participants with PM (Table 2).

\section{Clinical presentations of PM according to presence of poor sleep quality}

Participants with PM combined with poor sleep quality had higher proportion of anxiety $(p<0.001)$, depression $(p<0.001)$, and frequency of headache attack (median [interquartile range]: $2.0[0.3-4.0]$ vs. $1.0[0.2-2.0], p=$

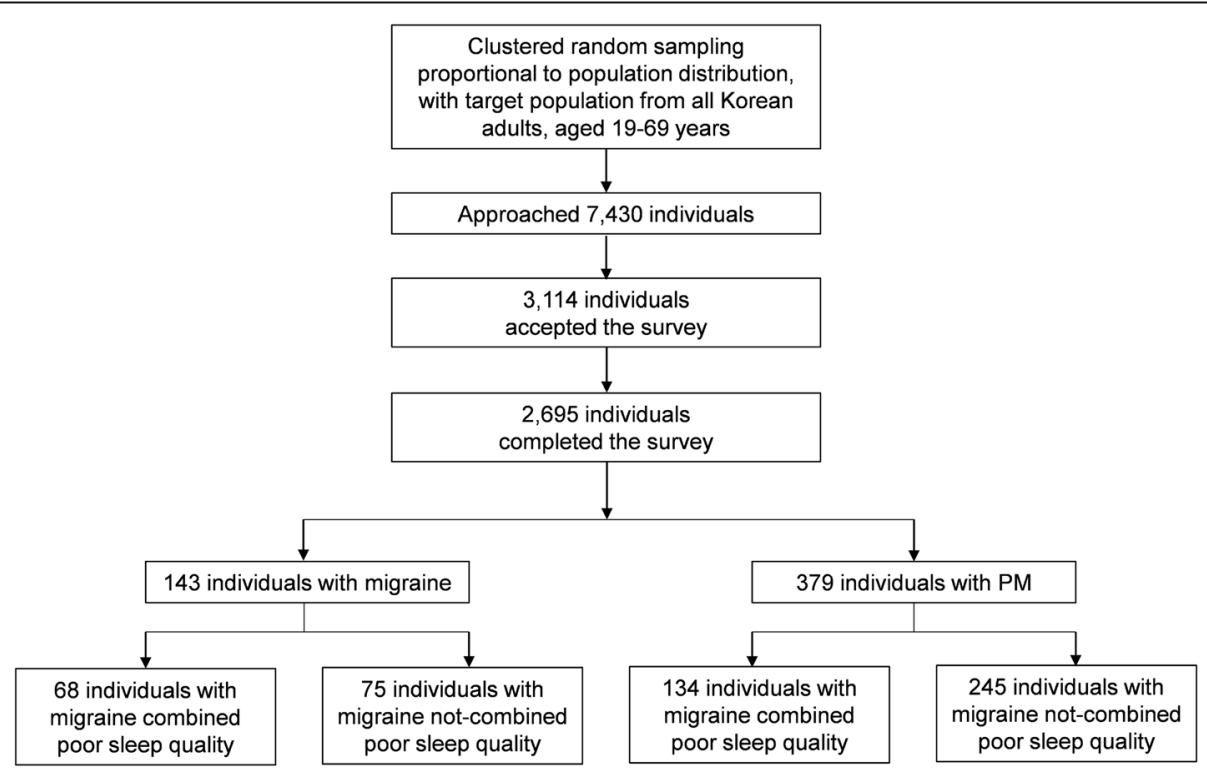

Fig. 1 Flowchart depicting enrolment and participation in the Korean Headache-Sleep Study 
Table 1 Sociodemographic characteristics of survey participants, the total Korean population, and cases identified as having migraine, probable migraine, and poor sleep quality

\begin{tabular}{|c|c|c|c|c|c|c|}
\hline Characteristic & $\begin{array}{l}\text { Survey participants } \\
N(\%)\end{array}$ & $\begin{array}{l}\text { Total population } \\
N(\%)\end{array}$ & $p$ & $\begin{array}{l}\text { Migraine N, \% } \\
(95 \% \mathrm{Cl})\end{array}$ & $\begin{array}{l}\text { Probable migraine } N, \% \\
(95 \% \mathrm{Cl})\end{array}$ & $\begin{array}{l}\text { Poor sleep quality N, \% (95\% Cl) } \\
\text { (PSQI > 5) }\end{array}$ \\
\hline \multicolumn{7}{|l|}{ Sex } \\
\hline Male & $1345(49.3)$ & $17,584,365(50.6)$ & $0.854^{\mathrm{a}}$ & $36,2.7(1.8-3.5)$ & $136,10.1(8.5-11.8)$ & $334,24.8(22.5-27.1)$ \\
\hline Female & $1350(50.7)$ & $17,198,350(49.4)$ & & $107,7.9(6.5-9.4)$ & $243,17.9(15.8-19.9)$ & $381,28.2(25.8-30.6$ \\
\hline \multicolumn{7}{|l|}{ Age, years } \\
\hline $19-29$ & $542(20.5)$ & $7,717,947(22.2)$ & $0.917^{a}$ & $25,4.5(2.7-6.2)$ & $69,12.6(9.8-15.4)$ & $153,28.3(24.4-32.0)$ \\
\hline $30-39$ & $604(21.9)$ & $8,349,487(24.0)$ & & $42,7.0(4.9-9.1)$ & $102,16.8(13.7-19.8)$ & $136,22.5(19.2-25.9)$ \\
\hline $40-49$ & $611(23.1)$ & $8,613,110(24.8)$ & & $39,6.5(4.5-8.4)$ & $102,16.8(13.9-19.8)$ & $167,27.3(23.8-30.1)$ \\
\hline $50-59$ & $529(18.9)$ & $6,167,505(17.7)$ & & $22,4.1(2.4-5.9)$ & $62,11.6(8.8-14.4)$ & $160,30.2(26.3-34.2)$ \\
\hline $60-69$ & 409 (15.6) & $3,934,666(11.3)$ & & $15,3.9(2.0-5.7)$ & $44,11.2(8.1-14.2)$ & $99,24.2(20.0-28.4)$ \\
\hline \multicolumn{7}{|c|}{ Size of the residential area } \\
\hline Large city & $1248(46.3)$ & $16,776,771(48.2)$ & $0.921^{\mathrm{a}}$ & $76,6.1(4.8-7.5)$ & $180,14.4(12.4-16.3)$ & $338,27.1(24.6-30.0)$ \\
\hline $\begin{array}{l}\text { Medium-to- } \\
\text { small city }\end{array}$ & $1186(44.0)$ & $15,164,345(43.6)$ & & $48,4.0(2.9-5.2)$ & $174,14.7(12.7-16.7)$ & $303,25.5(23.1-28.0)$ \\
\hline Rural area & $261(9.7)$ & $2,841,599(8.2)$ & & $19,7.4(4.2-10.6)$ & $25,9.7(6.1-13.3)$ & $74,28.4(22.8-33.9)$ \\
\hline \multicolumn{7}{|l|}{ Education level } \\
\hline $\begin{array}{l}\text { Middle school } \\
\text { or less }\end{array}$ & $393(14.9)$ & $6,608,716(19.0)$ & $0.752^{a}$ & $22,5.5(4.2-7.7)$ & $44,11.5(8.4-14.7)$ & $110,28.0(23.5-32.4)$ \\
\hline High school & $1208(44.5)$ & $15,234,829(43.8)$ & & $60,5.0(3.8-6.3)$ & $178,14.7(12.7-16.7)$ & $317,26.2(24.0-28.7)$ \\
\hline $\begin{array}{l}\text { College or } \\
\text { more }\end{array}$ & 1068 (39.6) & $12,939,170(37.2)$ & & $60,5.6(4.3-7.0)$ & $155,14.4(12.3-16.5)$ & $281,26.3(23.7-29.0)$ \\
\hline $\begin{array}{l}\text { Did not } \\
\text { respond }\end{array}$ & $26(9.6)$ & & & 1, $3.8(0.0-11.8)$ & $2,7.7(0.0-18.7)$ & 7, $26.9(8.7-45.2)$ \\
\hline Total & $2695(100.0)$ & $34,782,715(100.0)$ & & $143,5.3(4.5-6.2)$ & $379,14.1(12.7-15.4)$ & $715,26.5(24.8-28.2)$ \\
\hline
\end{tabular}

$\mathrm{N}$ number, $\mathrm{Cl}$ confidence interval, PSQI Pittsburgh Sleep Quality Index

${ }^{a}$ Compared with corresponding value reported in the general population of Korea

0.001 ) as well as higher headache intensity (VAS score, $6.0[4.0-7.0]$ vs. $5.0[3.5-6.0], p=0.003)$ and higher HIT-6 score (50.0 [44.0-58.0] vs. 44.0 [40.0-50.0], $p=$ 0.001) compared to participants with PM not combined with poor sleep quality (Table 3). Participants with migraine who combined with poor sleep quality had higher proportion of anxiety, depression, frequency of headache attack and higher HIT-6 score compared to participants with migraine who not combined with poor sleep quality (Table 3).

Table 2 Total and subcomponent PSQI scores among participants with no headache, probable migraine, and migraine

\begin{tabular}{|c|c|c|c|c|}
\hline Component & Non-headache $N=1422$ & Probable migraine $N=379$ & Migraine $N=143$ & $p$ value \\
\hline Subjective sleep quality & $1.7 \pm 0.8$ & $1.7 \pm 0.7$ & $1.7 \pm 0.7$ & 0.609 \\
\hline Sleep latency & $0.8 \pm 0.9$ & $1.0 \pm 1.0^{*}$ & $1.3 \pm 1.1^{\dagger \neq}$ & $<0.001$ \\
\hline Sleep duration & $0.4 \pm 0.8$ & $0.6 \pm 0.8^{*}$ & $0.5 \pm 0.8^{\dagger \neq}$ & 0.001 \\
\hline Habitual sleep efficacy & $0.0 \pm 1.5$ & $0.0 \pm 0.3$ & $0.0 \pm 0.0$ & 0.116 \\
\hline Sleep disturbance & $0.8 \pm 0.6$ & $0.9 \pm 0.6^{*}$ & $1.1 \pm 0.6^{\dagger \neq}$ & $<0.001$ \\
\hline Use of sleeping medication & $0.0 \pm 0.3$ & $0.1 \pm 0.4^{*}$ & $0.1 \pm 0.5^{\dagger}$ & 0.001 \\
\hline Daytime functioning & $0.5 \pm 0.7$ & $0.8 \pm 0.7^{*}$ & $0.9 \pm 0.9^{\dagger \neq}$ & $<0.001$ \\
\hline Total & $4.2 \pm 1.9$ & $5.2 \pm 2.4^{*}$ & $5.6 \pm 2.6^{\dagger \neq}$ & $<0.001$ \\
\hline
\end{tabular}

PSQI Pittsburgh Sleep Quality Index

Data are presented as mean \pm standard deviation

Each PSQI component score has a range of 0-3 points. Higher PSQI score indicates more severe disability

* $p<0.05$ for non-headache vs. probable migraine, by Tukey's post-hoc analysis

${ }^{\dagger} p<0.05$ for non-headache vs. migraine, by Tukey's post-hoc analysis

${ }^{\ddagger} p<0.05$ for probable migraine vs. migraine, by Tukey's post-hoc analysis 
Table 3 Demographics and clinical presentations of participants with migraine and probable migraine stratified according to the presence of poor sleep quality

\begin{tabular}{|c|c|c|c|c|c|c|}
\hline Characteristic & $\begin{array}{l}\text { Migraine with poor sleep } \\
\text { quality } N=68(47.5 \%)\end{array}$ & $\begin{array}{l}\text { Migraine without poor sleep } \\
\text { quality } N=75(52.5 \%)\end{array}$ & $\begin{array}{l}p \\
\text { value }\end{array}$ & $\begin{array}{l}\text { PM with poor sleep } \\
\text { quality } N=134(35.3 \%)\end{array}$ & $\begin{array}{l}\text { PM without poor sleep } \\
\text { quality } N=245(64.7 \%)\end{array}$ & $\begin{array}{l}p \\
\text { value }\end{array}$ \\
\hline \multicolumn{7}{|l|}{ Demographics } \\
\hline Age, years & $41.9 \pm 13.0$ & $40.6 \pm 11.9$ & 0.546 & $40.8 \pm 13.0$ & $42.5 \pm 12.4$ & 0.217 \\
\hline Female & $51(75.0)$ & $56(74.7)$ & 0.963 & $86(64.2)$ & $157(64.1)$ & 0.985 \\
\hline \multicolumn{7}{|c|}{ Headache characteristics } \\
\hline Bilateral pain & $36(52.9)$ & $45(60.0)$ & 0.395 & $73(54.5)$ & $148(60.4)$ & 0.263 \\
\hline $\begin{array}{l}\text { Non-pulsating } \\
\text { quality }\end{array}$ & $46(67.6)$ & $62(82.7)$ & 0.037 & $110(82.1)$ & $200(81.6)$ & 0.912 \\
\hline $\begin{array}{l}\text { Mild-to- } \\
\text { moderate } \\
\text { severity }\end{array}$ & $58(85.3)$ & $57(76.0)$ & 0.162 & $12(9.0)$ & $8(3.3)$ & 0.018 \\
\hline $\begin{array}{l}\text { Not aggravated } \\
\text { by movement }\end{array}$ & $48(70.6)$ & $52(69.3)$ & 0.870 & $85(63.4)$ & $151(61.6)$ & 0.730 \\
\hline \multicolumn{7}{|c|}{ Accompanying symptoms } \\
\hline Nausea & $59(86.8)$ & $66(88.0)$ & 0.824 & $117(87.3)$ & $20.7(84.5)$ & 0.456 \\
\hline Vomiting & $27(39.7)$ & $28(37.3)$ & 0.771 & $47(35.1)$ & $68(27.8)$ & 0.138 \\
\hline Photophobia & $41(60.3)$ & $43(57.3)$ & 0.719 & $70(52.2)$ & $110(44.9)$ & 0.171 \\
\hline Phonophobia & $50(73.5)$ & $51(68.0)$ & 0.468 & $101(75.4)$ & $167(68.2)$ & 0.140 \\
\hline Osmophobia & $35(51.5)$ & $33(44.0)$ & 0.372 & $71(53.0)$ & $108(44.1)$ & 0.097 \\
\hline \multicolumn{7}{|c|}{ Accompanying psychiatric problems } \\
\hline $\begin{array}{l}\text { Anxiety (GAS } \\
\text { score } \geq 5 \text { ) }\end{array}$ & $33(48.5)$ & $10(13.3)$ & $\begin{array}{l}< \\
0.001\end{array}$ & $43(32.1)$ & $24(9.8)$ & $\begin{array}{l}< \\
0.001\end{array}$ \\
\hline $\begin{array}{l}\text { Depression } \\
\text { (PHQ-9 score } \geq \\
\text { 10) }\end{array}$ & $19(27.9)$ & $5(6.7)$ & 0.001 & $28(20.9)$ & $5(2.0)$ & $\begin{array}{l}< \\
0.001\end{array}$ \\
\hline $\begin{array}{l}\text { Headache } \\
\text { frequency }\end{array}$ & $2.0(1.0-7.0)$ & $1.0(1.0-5.0)$ & 0.009 & $2.0(0.3-4.0)$ & $1.00(0.3-2.0)$ & 0.001 \\
\hline $\begin{array}{l}\text { VAS score for } \\
\text { headache intensity }\end{array}$ & $7.0(4.0-10.0)$ & $6.0(4.0-8.0)$ & 0.247 & $6.0(4.0-7.0)$ & $5.00(3.5-6.0)$ & 0.003 \\
\hline HIT-6 score & $57.5(50.0-65.0)$ & $50.0(43.0-57.0)$ & $\begin{array}{l}< \\
0.001\end{array}$ & $50.0(44.0-58.0)$ & $44.0(40.0-50.0)$ & $\begin{array}{l}< \\
0.001\end{array}$ \\
\hline
\end{tabular}

Data are presented as mean \pm standard deviation, number (percent), or median (interquartile range)

PM probable migraine, GAS Goldberg Anxiety Scale, PHQ Patient Health Questionnaire, VAS visual analogue scale, HIT Headache Impact Test

Table 4 Analysis ${ }^{a}$ of contributing factors related to the total PSQI score in participants with probable migraine

\begin{tabular}{|c|c|c|c|c|c|c|c|}
\hline \multirow[t]{2}{*}{ Factor } & \multicolumn{2}{|c|}{ Unstandardized coefficients } & \multirow{2}{*}{$\begin{array}{l}\text { Standardized coefficients } \\
\beta\end{array}$} & \multirow[t]{2}{*}{ T } & \multirow{2}{*}{$\begin{array}{l}p \\
\text { value }\end{array}$} & \multirow[t]{2}{*}{ Tolerance } & \multirow[t]{2}{*}{ VIF } \\
\hline & $\mathrm{B}$ & SE & & & & & \\
\hline Age & -0.086 & 0.085 & -0.046 & -1.019 & 0.309 & 0.810 & 1.235 \\
\hline Sex & -0.177 & 0.202 & -0.036 & -0.877 & 0.381 & 0.969 & 1.032 \\
\hline Size of residential area & -0.086 & 0.157 & -0.022 & -0.548 & 0.584 & 0.988 & 1.012 \\
\hline Educational level & -0.082 & 0.131 & -0.028 & -0.629 & 0.529 & 0.792 & 1.262 \\
\hline Anxiety (GAS score $\geq 5$ ) & 0.231 & 0.052 & 0.230 & 4.438 & $<0.001$ & 0.602 & 1.660 \\
\hline Depression (PHQ-9 score $\geq 10$ ) & 0.230 & 0.027 & 0.426 & 8.471 & $<0.001$ & 0.640 & 1.563 \\
\hline Headache frequency per month & 0.039 & 0.018 & 0.090 & 2.166 & 0.031 & 0.928 & 1.077 \\
\hline VAS score for headache intensity & 0.088 & 0.056 & 0.065 & 1.556 & 0.121 & 0.923 & 1.083 \\
\hline
\end{tabular}

PSQI Pittsburgh Sleep Quality Index, SE standard error, VIF variation inflation factor, GAS Goldberg Anxiety Scale, PHQ Patient Health Questionnaire, VAS visual analogue scale

Independent variables included sociodemographic variables (age, sex, size of residential areas, and education level), anxiety (GAS score $\geq 5$ ), depression (PHQ-9 score $\geq 10$ ), headache frequency per month, and VAS score for headache intensity, whereas total PSQI score was included as the dependent variable

a multivariate linear regression: $R^{2}=0.194$, adjusted $R^{2}=0.139$ 


\section{Factors associated with PSQI score among PM} participants

In multivariable linear regression analysis, anxiety $(\beta=$ $0.230, p<0.001)$, depression $(\beta=0.426, p<0.001)$, and headache frequency per month $(\beta=0.090, p=0.031)$ were significant independent factors associated with total PSQI score in participants with PM (Table 4).

\section{Discussion}

The main findings of our research were as follows. First, prevalence of migraine, PM, and poor sleep quality in Korean general population were $5.3 \%, 14.1 \%$, and $26.5 \%$, respectively. Second, $35.3 \%$ of participants with PM had poor sleep quality, which was lower than the prevalence noted in participants with migraine, but higher than that in participants with non-headache. Third, among PM participants, those with poor sleep quality showed increased headache frequency, intensity, and impact.

Among migraineurs, poor sleep quality is not an uncommon problem. A clinic-based study in India has reported that $66.7 \%$ of migraineurs without aura show poor sleep quality. This proportion is higher than that in non-migraine participants [14]. A Chinese study investigating 1023 nurses has demonstrated that, compared to tension-type headache or non-headache participants, migraineurs have reported significantly higher frequency of poor sleep quality [27]. In our study, the first to assess the prevalence of poor sleep quality among individuals with $\mathrm{PM}$ in a population-based setting, approximately half of migraineurs and one-third of individuals with PM experienced poor sleep quality. This confirms that poor sleep quality is a common comorbidity not only in migraineurs, but also in individuals with PM.

Among PSQI components, latency of sleep, duration of sleep, sleep disturbance, hypnotics use, and daytime dysfunction scores were significantly higher in participants with PM than those in non-headache participants. This suggests that various aspects of sleep quality are impaired in individuals with PM. One interesting finding is the impairment of daytime functioning among participants with PM. Indeed, individuals with migraine or PM often report disability even during interictal period [28]. Migraineurs are less physically active with reduced vigour. They show higher levels of sleepiness and more anxiety and avoidance [28]. Our findings are in line with results of previous observation [28], additionally indicating that daytime dysfunction in PM patients might be associated with poor sleep quality.

Our study demonstrated that anxiety, depression, and headache frequency were associated with poor sleep quality. This is in agreement with previous observations showing that anxiety and depression are independently related factors for PSQI score [29, 30] and that headache frequency is positively associated with PSQI score among migraineurs [31]. Our results confirmed that anxiety, depression, and headache frequency were significant factors for PSQI score among individuals with PM.

Insomnia is a prevalent sleep disorder. Individuals with insomnia may have difficulty falling asleep, staying asleep or early awakening even if enough time is given [32]. Poor sleep quality can occur as a result of insomnia [33]. Nevertheless, it can be caused by other conditions such as sleep apnea, shift working, use of medications, environmental factors et al. [34-37]. Therefore, the poor sleep quality is related to insomnia but measures border sleep difficulties. We already investigated the association of poor sleep quality and migraine in a population-based sample [38]. Here, we firstly report the relationship of poor sleep quality and PM, another common and disabling headache disorder.

Based on findings of the present study, we propose the following strategies to improve sleep quality in participants with PM. Since anxiety, depression, and headache frequency are independent factors associated with poor sleep quality in individuals with PM, they could be successfully managed by pharmacological and non-pharmacological treatments. Anxiolytic drugs and antidepressants are effective in reducing anxiety and depression symptoms [39]. Non-pharmacological cognitive behaviour therapy (CBT) can be used to treat anxiety and depression [40]. Headache frequency can be reduced by preventive pharmacological treatment and non-pharmacological treatments such as relaxation techniques, CBT, education, and mindfulness [41]. Therefore, pharmacological and non-pharmacological treatments of anxiety, depression, and headache frequency might be able to improve sleep quality of individuals with PM. Such strategies may improve symptoms of PM by improving sleep quality.

In the present study, PM participants with poor sleep quality had more headache frequency and more severe headaches than PM participants without poor sleep quality. Considering that headache frequency and intensity are closely associated with headache-related disability and health-related quality of life, poor sleep quality may be an important factor for such aspects in individuals with PM [42]. Sleep quality may be improved using pharmacological and non-pharmacological treatments [43]. Our present findings suggest that, among individuals with PM, proper assessment and treatment of poor sleep quality may be needed to reduce headache-related disability and improve quality of life besides improving headache symptoms.

Our research has some limitations. First, although questionnaire was utilized to the diagnosis of PM and migraine, this questionnaire was only validated in migraine, but not validated in PM. According to ICHD-2, the diagnosis of PM is diagnosed only when one of the 
criteria of migraine is not satisfied. Thus, validation for PM itself is not necessarily required. Second, we evaluated sleep quality using a questionnaire without performing actigraphy or polysomnography to confirm the sleep quality objectively. Nevertheless, we found it not only practical, but also appropriate to use PSQI because this tool was validated for assessing sleep quality, showing good agreement with polysomnography and actigraphy measurements [44]. Therefore, it has been widely adopted in clinical and epidemiological studies. Third, although our study was population-based with low sampling error, its statistical power was limited because our study could not preform subgroup analysis due to limited sample size. Lastly, we did not included medications for migraine and PM treatment in analyses. Although a significant proportion of migraineurs did not receive medical treatment, some medications for acute and preventive treatments may influence on sleep quality. Caffeine, a common ingredient of acute migraine treatment, may impair sleep quality [45]. Topiramate is a widely used medication for preventive migraine treatment and may induce dysphoria or unmask latent mood disorder [46]. Further studies are needed the effect of migraine medications on sleep quality among individuals of migraine and PM.

On the other hand, the present study has several strengths. First, our study used a questionnaire whose Korean version was specifically validated for assessing migraine, anxiety, depression, and sleep quality. Second, we applied clustered random sampling proportional to the distribution in the Korean general population with low sampling error which allowed us to accurately assess the prevalence of migraine, PM, and poor sleep quality. Third, we investigated PSQI component scores in addition to total scores. PSQI comprises seven components including subjective sleep quality, latency of sleep, duration of sleep, habitual sleep efficacy, sleep disturbance, use of hypnotics, and dysfunction at daytime. By investigating these various aspects of sleep quality separately, we were able to determine that some components were impaired in participants with PM.

\section{Conclusion}

Although the prevalence of poor sleep quality was lower in participants with PM than that in migraineurs, prevalence remained high in those with PM. It was associated with worse symptoms of PM. Our results suggest that appropriate diagnostic approach and management of poor sleep quality are necessary to manage PM appropriately.

\section{Additional file}

Additional file 1: Raw data of the present study. (XLS $1035 \mathrm{~kb})$

\section{Abbreviations}

HIT-6: Headache impact test-6; ICHD: International classification of headache disorders; KHSS: Korean headache-sleep study; PHQ-9: Patient health questionnaire-9; PM: Probable migraine; PSQI: Pittsburgh sleep quality index; VAS: Visual analogue scale

\section{Acknowledgements}

The authors would like to thank Gallup Korea for providing technical support for the Korean Headache-Sleep Study.

\section{Funding}

This Study was supported by a 2011-Grant from Korean Academy of Medical Sciences. This research was also supported by a grant

(2018R1D1A1B07040959) of the Basic Science Research Program through the National Research Foundation (NRF) funded by the Ministry of Education, Republic of Korea.

\section{Availability of data and materials}

The dataset supporting the conclusions of this article is included within the article and its Additional file 1.

\section{Authors' contributions}

T-JS, S-JC, W-JK, KIY, C-HY, and MKC contributed to the design of the analysis and interpretation of the data. T-JS and MKC drafted the paper with contributions from all authors. All authors approved the final version of the manuscript.

\section{Ethics approval and consent to participate}

The KHSS was approved by Institutional Review Board of Hallym University Sacred Heart Hospital (approval No. 2011-1077). We received written consent from all participants before survey interview.

\section{Consent for publication}

Not applicable.

\section{Competing interests}

Tae-Jin Song has no potential conflicts of interest.

Soo-Jin Cho was a site investigator of multicenter trial sponsored by Otsuka Korea, Eli Lilly and Company, Korea BMS, and Parexel Korea Co., Ltd.. Soo-Jin Cho also worked as an advisory member for Teva. Soo-Jin Cho received research support from Hallym University Research Fund 2016 and Academic award of Myung In Pharm. Co. Ltd. Soo-Jin Cho also received lecture honoraria from Yuyu Pharmaceutical Company and Allergan Korea.

Won-Joo Kim has no potential conflicts of interest.

Kwang Ik Yang has no potential conflicts of interest.

Chang-Ho Yun has no potential conflicts of interest.

Min Kyung Chu was a site investigator for a multi-center trial sponsored by Eli Lilly and company; worked an advisory member for Teva, and received lecture honoraria from Allergan Korea and Yuyu Pharmaceutical Company in the past 24 months. The authors declare that they have no competing interest.

\section{Publisher's Note}

Springer Nature remains neutral with regard to jurisdictional claims in published maps and institutional affiliations.

\footnotetext{
Author details

'Department of Neurology, College of Medicine, Ewha Womans University, Seoul, South Korea. ${ }^{2}$ Department of Neurology, Dongtan Sacred Heart Hospital, Hallym University College of Medicine, Hwaseong, South Korea. ${ }^{3}$ Department of Neurology, Gangnam Severance Hospital, Yonsei University, College of Medicine, Seoul, South Korea. ${ }^{4}$ Department of Neurology, Soonchunhyang University College of Medicine, Cheonan Hospital, Cheonan, South Korea. ${ }^{5}$ Department of Neurology, Clinical Neuroscience Center, Seoul National University Bundang Hospital, Seongnam, South Korea. ${ }^{6}$ Department of Neurology, Yonsei University College of Medicine, 50-1 Yonsei-ro, Seodaemoon-gu, Seoul 03722, South Korea.
} 
Received: 29 May 2018 Accepted: 13 July 2018

\section{Published online: 25 July 2018}

\section{References}

1. Headache Classification Committee of the International Headache Society (IHS) The International Classification of Headache Disorders, 3rd edition (2018). Cephalalgia 38 (1):1-211. http://journals.sagepub.com/toc/cepa/38/1

2. Bigal M, Kolodner K, Lafata J, Leotta C, Lipton R (2006) Patterns of medical diagnosis and treatment of migraine and probable migraine in a health plan. Cephalalgia 26(1):43-49

3. Lantéri-Minet M, Valade D, Geraud G, Chautard M, Lucas C (2005) Migraine and probable migraine-results of FRAMIG 3, a French nationwide survey carried out according to the 2004 IHS classification. Cephalalgia 25(12):1146-1158

4. Patel N, Bigal M, Kolodner K, Leotta C, Lafata JE, Lipton R (2004) Prevalence and impact of migraine and probable migraine in a health plan. Neurology 63(8):1432-1438

5. Kim BK, Chung YK, Kim JM, Lee KS, Chu MK (2013) Prevalence, clinical characteristics and disability of migraine and probable migraine: a nationwide population-based survey in Korea. Cephalalgia 33(13):1106-1116

6. Uhlig BL, Engstrom M, Odegard SS, Hagen KK, Sand T (2014) Headache and insomnia in population-based epidemiological studies. Cephalalgia 34(10):745-751

7. Kim J, Cho SJ, Kim WJ, Yang Kl, Yun CH, Chu MK (2016) Excessive daytime sleepiness is associated with an exacerbation of migraine: a populationbased study. J Headache Pain 17(1):62

8. Scher Al, Lipton RB, Stewart WF (2003) Habitual snoring as a risk factor for chronic daily headache. Neurology 60(8):1366-1368

9. Fernandes G, Franco AL, Goncalves DA, Speciali JG, Bigal ME, Camparis CM (2013) Temporomandibular disorders, sleep bruxism, and primary headaches are mutually associated. J Orofac Pain 27(1):14-20

10. Schurks M, Winter A, Berger K, Kurth T (2014) Migraine and restless legs syndrome: a systematic review. Cephalalgia 34(10):777-794

11. Pilcher JJ, Ginter DR, Sadowsky B (1997) Sleep quality versus sleep quantity: relationships between sleep and measures of health, well-being and sleepiness in college students. J Psychosom Res 42(6):583-596

12. Bruni O, Russo PM, Violani C, Guidetti V (2004) Sleep and migraine: an actigraphic study. Cephalalgia 24(2):134-139

13. Nayak C, Sinha S, Nagappa M, Nagaraj K, Kulkarni GB, Thennarasu K, Taly AB (2016) Study of sleep microstructure in patients of migraine without aura. Sleep Breath 20(1):263-269

14. Karthik N, Kulkarni GB, Taly AB, Rao S, Sinha S (2012) Sleep disturbances in 'migraine without aura'--a questionnaire based study. J Neurol Sci 321(1-2):73-76

15. Seidel S, Hartl T, Weber M, Matterey S, Paul A, Riederer F, Gharabaghi M, Wober-Bingol C, Wober C, Group PS (2009) Quality of sleep, fatigue and daytime sleepiness in migraine - a controlled study. Cephalalgia 29(6):662-669

16. Zhu Z, Fan X, Li X, Tan G, Chen L, Zhou J (2013) Prevalence and predictive factors for poor sleep quality among migraineurs in a tertiary hospital headache clinic. Acta Neurol Belg 113(3):229-235

17. Oh K, Cho SJ, Chung YK, Kim JM, Chu MK (2014) Combination of anxiety and depression is associated with an increased headache frequency in migraineurs: a population-based study. BMC Neurol 14:238

18. Headache Classification Subcommittee of the International Headache Society (2004) The International Classification of Headache Disorders: 2nd edition. Cephalalgia 24(1):9-160

19. Stang PE, Osterhaus JT (1993) Impact of migraine in the United States: data from the National Health Interview Survey. Headache 33(1):29-35

20. Kim BK, Chu MK, Lee TG, Kim JM, Chung CS, Lee KS (2012) Prevalence and impact of migraine and tension-type headache in Korea. J Clin Neurol 8(3): 204-211

21. Buysse DJ, Reynolds CF 3rd, Monk TH, Berman SR, Kupfer DJ (1989) The Pittsburgh sleep quality index: a new instrument for psychiatric practice and research. Psychiatry Res 28(2):193-213

22. Goldberg D, Bridges K, Duncan-Jones P, Grayson D (1988) Detecting anxiety and depression in general medical settings. BMJ 297(6653):897-899

23. Lim JY, Lee SH, Cha YS, Park HS, Sunwoo S (2001) Reliability and validity of anxiety screening scale. J Korean Acad Fam Med 22(8):1224-1232

24. Kim JS, Kim SY, Lee GY, Park TJ, Lee YH, Kong BK (1997) The standardization of Korean-translated Goldberg's shart screening scale for anxiety and depression. Korean J Fam Med 18:1452-1460
25. Pignone MP, Gaynes BN, Rushton JL, Burchell CM, Orleans CT, Mulrow CD, Lohr KN (2002) Screening for depression in adults: a summary of the evidence for the US preventive services task force. Ann Intern Med 136(10):765-776

26. Choi HS, Choi JH, Park KH, Joo KJ, Ga H, Ko HJ, Kim SR (2007) Standardization of the Korean version of patient health Questionnaire-9 as a screening instrument for major depressive disorder. J Korean Acad Fam Med 28(2):114-119

27. Wang Y, Xie J, Yang F, Wu S, Wang H, Zhang X, Liu H, Deng X, Xie W, Yu S (2015) Comorbidity of poor sleep and primary headaches among nursing staff in North China. J Headache Pain 16:88

28. Lampl C, Thomas H, Stovner LJ, Tassorelli C, Katsarava Z, Lainez JM, LanteriMinet M, Rastenyte D, Ruiz de la Torre E, Andree C, Steiner TJ (2016) Interictal burden attributable to episodic headache: findings from the Eurolight project. J Headache Pain 17:9

29. Feng Q, Zhang QL, Du Y, Ye YL, He QQ (2014) Associations of physical activity, screen time with depression, anxiety and sleep quality among Chinese college freshmen. PLoS One 9(6):e100914

30. Shim J, Kang SW (2017) Behavioral factors related to sleep quality and duration in adults. J Lifestyle Med 7(1):18-26

31. Lin YK, Lin GY, Lee JT, Lee MS, Tsai CK, Hsu YW, Lin YZ, Tsai YC, Yang FC (2016) Associations between sleep quality and migraine frequency: a crosssectional case-control study. Medicine (Baltimore) 95(17):e3554

32. Roth T (2007) Insomnia: definition, prevalence, etiology, and consequences. J Clin Sleep Med 3(5 Suppl):S7-S10

33. Morin CM, Belleville $G$, Belanger $L$, Ivers $H$ (2011) The insomnia severity index: psychometric indicators to detect insomnia cases and evaluate treatment response. Sleep 34(5):601-608

34. Macey PM, Woo MA, Kumar R, Cross RL, Harper RM (2010) Relationship between obstructive sleep apnea severity and sleep, depression and anxiety symptoms in newly-diagnosed patients. PLoS One 5(4):e10211

35. Agargun MY, Tekeoglu I, Gunes A, Adak B, Kara H, Ercan M (1999) Sleep quality and pain threshold in patients with fibromyalgia. Compr Psychiatry 40(3):226-228

36. Elliott JL, Lal S (2016) Blood pressure, sleep quality and fatigue in shift working police officers: effects of a twelve hour roster system on cardiovascular and sleep health. Int J Environ Res Public Health 13(2):172

37. Genderson MR, Rana BK, Panizzon MS, Grant MD, Toomey R, Jacobson KC, Xian H, Cronin-Golomb A, Franz CE, Kremen WS, Lyons MJ (2013) Genetic and environmental influences on sleep quality in middle-aged men: a twin study. J Sleep Res 22(5):519-526

38. Song TJ, Yun CH, Cho SJ, Kim WJ, Yang Kl, Chu MK (2018) Short sleep duration and poor sleep quality among migraineurs: a population-based study. Cephalalgia 38(5):855-864

39. Farach FJ, Pruitt LD, Jun JJ, Jerud AB, Zoellner LA, Roy-Byrne PP (2012) Pharmacological treatment of anxiety disorders: current treatments and future directions. J Anxiety Disord 26(8):833-843

40. Hofmann SG, Asnaani A, Vonk IJ, Sawyer AT, Fang A (2012) The efficacy of cognitive behavioral therapy: a review of meta-analyses. Cognit Ther Res 36(5):427-440

41. Probyn K, Bowers H, Mistry D, Caldwell F, Underwood M, Patel S, Sandhu HK, Matharu M, Pincus T (2017) Non-pharmacological self-management for people living with migraine or tension-type headache: a systematic review including analysis of intervention components. BMJ Open 7(8):e016670

42. Bagley $\mathrm{CL}$, Rendas-Baum R, Maglinte GA, Yang M, Varon SF, Lee J, Kosinski M (2012) Validating migraine-specific quality of life questionnaire V2.1 in episodic and chronic migraine. Headache 52(3):409-421

43. Khawaja IS, Dieperink ME, Thuras P, Kunisaki KM, Schumacher MM, Germain A, Amborn B, Hurwitz TD (2013) Effect of sleep skills education on sleep quality in patients attending a psychiatry partial hospitalization program. Prim Care Companion CNS Disord 15(1)

44. Landry GJ, Best JR, Liu-Ambrose T (2015) Measuring sleep quality in older adults: a comparison using subjective and objective methods. Front Aging Neurosci 7:166

45. Lohsoonthorn V, Khidir H, Casillas G, Lertmaharit S, Tadesse MG, Pensuksan WC, Rattananupong T, Gelaye B, Williams MA (2013) Sleep quality and sleep patterns in relation to consumption of energy drinks, caffeinated beverages, and other stimulants among Thai college students. Sleep Breath 17(3):1017-1028

46. Janowsky DS, Kraus JE, Barnhill J, Elamir B, Davis JM (2003) Effects of topiramate on aggressive, self-injurious, and disruptive/destructive behaviors in the intellectually disabled: an open-label retrospective study. J Clin Psychopharmacol 23(5):500-504 